\title{
Assessment of quality of life in type 2 diabetes mellitus patients using World Health Organization quality of life-BREF questionnaire and appraisal of diabetes scale - a cross-sectional study
}

\author{
Supriya Patil, ${ }^{1}$ Yamini Patil, ${ }^{2}$ Sanjay Kumar Patil ${ }^{2}$ \\ ${ }^{1}$ Department of Preventive and Social Medicine (PSM); and ${ }^{2}$ Department of Obstetrics and Gynecology, Krishna Institute of \\ Medical Sciences, Karad (Maharashtra), India
}

\begin{abstract}
Diabetes is a chronic metabolic disorder that disturbs the quality of life (QOL) of patients. Therefore, evaluation of diabetes-related QOL could be a key outcome measure for its management. This study assessed the QOL in type 2 diabetes mellitus (T2DM) patients using the World Health Organization (WHO) quality of life (QOL)-BREF questionnaire and disease-specific appraisal of diabetes scale (ADS). In this cross-sectional study, 520 T2DM patients were included. Patients' demographic data, clinical information was collected through interviews, and the WHOQOL-BREF instrument and ADS were used for the QOL of patients. Statistical analysis was performed by using R software (Version 3.6.0). The mean ADS scores were lower in controlled diabetic subjects (18.50 \pm 3.08$)$ and higher in uncontrolled diabetic subjects $(19.29 \pm 2.73)(\mathrm{P}<0.05)$. For WHOQOL-BREF, the mean scores for all the domains (overall general health, physical, psychological, social, and environmental) were significantly higher in controlled diabetic subjects $(\mathrm{P}<0.001)$. In addition, the age, duration of diabetes, associated comorbidities, treatment, and HbA1c level of patients showed a highly significant correlation with WHOQOL-BREF $(\mathrm{P}<0.001)$. Diabetic patients had poor-to-average QOL. Therefore, public health measures and education of diabetic patients are essential to create more awareness for improving the QOL of T2DM.
\end{abstract}

\section{Introduction}

Diabetes mellitus (DM) causes secondary pathophysiological changes due to associated metabolic

Correspondence: Sanjay Patil, Department of Obstetrics and Gynecology, Krishna Institute of Medical Sciences, Karad (Maharashtra), 415110 India. Tel.: +91.9422496314.

E-mail: dryspmaher@gmail.com

Key words: Quality of life; diabetes mellitus; questionnaires; comorbidity; World Health Organization.

Contributions: SP, literature search, experimental studies, data acquisition, statistical analysis, manuscript preparation; SKP, manuscript editing and review; SP, YP, definition of intellectual content, clinical studies, data analysis; YP, SKP, study design; SP, YP, SKP, study concept and guarantors.

Conflict of interests: the authors declare no potential conflict of interests.

Received for publication: 10 December 2020.

Revision received: 10 May 2021.

Accepted for publication: 10 May 2021.

This work is licensed under a Creative Commons Attribution NonCommercial 4.0 License (CC BY-NC 4.0).

${ }^{\circ}$ Copyright: the Author(s), 2021

Licensee PAGEPress, Italy

Italian Journal of Medicine 2021; 15:164-169

doi:10.4081/itjm.2021.1444 dysregulation resulting in tremendous pressure on the quality of life (QOL) of the diabetic individual. Individuals with type 2 DM (T2DM) are at 2-4 times greater risk for coronary heart disease, which is the $9^{\text {th }}$ major cause of death. ${ }^{1}$ Globally, around 1 adult among 11 have DM, and $90 \%$ of them have T2DM. The epicenter for this rapidly emerging T2DM global epidemic is Asia, with China and India topping the list. ${ }^{2}$ India had 62.4 million cases of T2DM in 2011. It is estimated that by 2030 , India will have 100 million people with diabetes. ${ }^{2}$

QOL is a broad concept. In a complex way, it is affected by an individual's psychological state, physical health, social relationships, personal beliefs, level of independence, and relationship with their environment. ${ }^{3}$ The evaluation of QOL is considered an important outcome measure for the management of chronic diseases. ${ }^{4}$ The mental status and psychosocial behavior of diabetic patients affect their self-care behavior leading to impaired QOL and the risk of developing longterm complications. ${ }^{3}$

It is obligatory to use generic, disease-specific, and situation-specific instruments to evaluate patient-assessed outcomes (QOL) for diabetes. ${ }^{5}$ The World Health Organization quality of life-BREF (WHOQOL-BREF) is one such generic instrument, ${ }^{4}$ designed to measure the health aspects that are universally essential and can be used for comparing healthy populations or two different groups of pa- 
tients. ${ }^{4}$ The appraisal of diabetes scale (ADS) is a disease-specific instrument that can make such generic instruments more responsive to health changes. ${ }^{6}$ Together, these instruments help in a more accurate and detailed assessment of patient-related concerns and are essential endpoints in studies designed to measure changes in QOL.?

Several studies have been performed on the QOL in T2DM from developed and developing countries and have shown that poor QOL leads to worsening glycemic control, increased hospital visits, poor sleep, and restricted social life. ${ }^{8-10}$ Due to the increased incidence of T2DM in India, it becomes essential to measure the QOL for improved care and control. ${ }^{11}$ Thus, the purpose of this study was to assess the QOL in T2DM patients using the WHOQOL-BREF questionnaire and disease-specific ADS.

\section{Materials and Methods}

\section{Study design}

With the institutional ethics committee's approval (Approval number- KIMSDU/IEC/03/2017), this cross-sectional study was conducted at a tertiary care hospital in Karad (Maharashtra) for 19 months (December 2017-June 2019). Informed consent was obtained from all the patients included in the study. The sample size was calculated by using the standard formula, by considering the prevalence of poor (dissatisfied lifestyle/low scores) QOL in T2DM as 39\%. ${ }^{12,13}$

\section{Selection criteria}

Five hundred and twenty patients of either sex, diagnosed with T2DM, aged 31-90 years, and on drug therapy for at least 1 month were included in the study. Patients with type $1 \mathrm{DM}$, gestational DM, newly diagnosed diabetes, and patients not willing to participate were excluded from the study.

\section{Data collection}

A structured questionnaire was used to collect the socio-demographic information (age, sex, marital status, religion, education, occupation, family type, total members in the family, monthly income and monthly per capita income, social habits, food habits, exercise habits, and BG Prasad class status), ${ }^{14,15}$ anthropometric measurements (height, weight, and body mass index [BMI]) along with diabetes-related information such as family history, past medical history, duration of diabetes, whether undergoing treatment, disease symptoms, postprandial glucose (PPBG) level, fasting blood glucose (FBG) level, and glycosylated hemoglobin level (HbAlc) needed by the study.

Patients with $\mathrm{HbA} 1 \mathrm{c}<7 \%$ were considered con- trolled diabetics, while patients with $\mathrm{HbAlc}>7 \%$ were considered uncontrolled diabetics. WHOQOLBREF questionnaire ${ }^{4}$ was used to assess the QoL, and ADS questionnaire ${ }^{6}$ was used to assess the status of diabetes. WHOQOL-BREF questionnaire is a 26 -item generic questionnaire assessing the individual's perception towards their culture and value system and their personal goal, standards, and concerns. All the items were classified in five domains: global-overall general health (two items), physical (seven items), psychological (six items), social relationships (three items), and environment (8 items) and were scored on a five-point Likert scale and a low score indicating poor QOL. ADS questionnaire is a seven-item diabetes-specific scale addressing the patient's perception towards their feeling and attitudes about diabetes. This questionnaire consists of uncertainty due to diabetes, anticipated future deterioration, distress caused by diabetes, control over diabetes, and effect of diabetes on life goals scored on a five-point Likert scale and a low score indicating good QOL.

\section{Statistical analysis}

Statistical analysis was performed by using R software (Version. 3.6.0). Data were recorded in Microsoft Excel and expressed as mean \pm standard deviation with frequency and percentage. Qualitative variables were analyzed using the Chi-square test of independence, and the unpaired ' $t$ ' test was used to test the difference between the two groups. Data were considered statistically significant when $\mathrm{P} \leq 0.05$.

\section{Results}

This study was carried out on 520 T2DM patients. Table 1 presents the socio-demographic data of all the patients. The majority of the patients were in the age group of 51-60 years with male predominance (male: female $=1: 0.9$ ). Most of the patients was married, belonged to Class III economic class, and was from a joint family, which implied more responsibilities leading to more stress, which could be one of the risk factors for T2DM (Table 1).

Most of the male patients were middle-aged and doing business, while the majority of the female patients were housewives and had reached old age. The BMI data revealed that $40.9 \%$ of the subjects had their BMI within the normal range $\left(18.5-22.9 \mathrm{~kg} / \mathrm{m}^{2}\right)$. In addition, most patients of either gender had completed either primary or secondary school, passing out stipulating low education level (Table 2).

The clinical profile of most patients indicated a family history of diabetes, stipulating that the genetic profile could be a major risk factor. Most patients had diabetes from 0 to 10 years of age. Polyuria was noted 
to be the most common symptom indicative of uncontrolled bladder activity in diabetic patients. Furthermore, as diabetes results in comorbidities, the majority of the patients showed multiple comorbidities along with hypertension. Although oral hypoglycemic agents were most used for treatment, some patients were using both insulins and oral hypoglycemic agents. Although fasting and postprandial blood glucose levels were mostly under control, most patients had their hemoglobin A1c levels above the normal range due to diabetes (Table 3 ).

The age, duration of diabetes, associated comorbidities, treatment, and $\mathrm{HbA} 1 \mathrm{c}$ level of patients showed a highly significant correlation with QOL, assessed by WHOQOL-BREF $(\mathrm{P}<0.001)$. However, no significant correlation was observed between the BMI of patients and WHOQOL-BREF ( $>0.05)$ (Table 4).

Table 1. Socio-demographic characteristics of the patients.

\begin{tabular}{|c|c|}
\hline Socio-demographics & Patients No. (\%) \\
\hline \multicolumn{2}{|l|}{ Age range (years) } \\
\hline $31-40$ & $12(2.3)$ \\
\hline $41-50$ & $79(15.2)$ \\
\hline $51-60$ & $198(38.1)$ \\
\hline $61-70$ & $188(36.2)$ \\
\hline $71-80$ & $37(7.1)$ \\
\hline $81-90$ & $6(1.2)$ \\
\hline \multicolumn{2}{|l|}{ Sex } \\
\hline Male & $264(50.76)$ \\
\hline Female & $256(49.24)$ \\
\hline \multicolumn{2}{|l|}{ Marital status } \\
\hline Married & $389(74.8)$ \\
\hline Widowed/widower & $123(23.7)$ \\
\hline Unmarried/divorced & $8(1.5)$ \\
\hline \multicolumn{2}{|l|}{ Type of family } \\
\hline Nuclear & $172(34.23)$ \\
\hline Joint & $348(66.92)$ \\
\hline \multicolumn{2}{|l|}{ Religion } \\
\hline Hindu & $343(65.96)$ \\
\hline Muslim & $94(18.07)$ \\
\hline Christian & $64(12.3)$ \\
\hline Others & $19(3.65)$ \\
\hline \multicolumn{2}{|c|}{ B.G Prasad class status (economic class) } \\
\hline Class I & $20(3.8)$ \\
\hline Class II & $114(21.9)$ \\
\hline Class III & $226(43.5)$ \\
\hline Class IV & $136(26.2)$ \\
\hline Class V & $24(4.6)$ \\
\hline Do not know & $221(42.50)$ \\
\hline \multicolumn{2}{|l|}{ Diet pattern } \\
\hline Vegetarian & $280(53.8)$ \\
\hline Non-vegetarian & $59(11.3)$ \\
\hline Both veg and non-veg & $181(34.8)$ \\
\hline \multicolumn{2}{|l|}{ Frequency of exercise } \\
\hline Regular & $347(66.7)$ \\
\hline Occasional & $65(12.5)$ \\
\hline No exercise & $108(20.8)$ \\
\hline
\end{tabular}

No (\%), number (percentage).
The mean ADS score was $19.03 \pm 2.87$ (range: 12 28). A significant difference in the ADS scores $(\mathrm{P}<0.05)$ was observed between controlled and uncontrolled diabetes, suggesting that patients' QOL was more affected in uncontrolled diabetes than in controlled diabetes. All the 5 domains of WHOQOLBREF also showed a highly significant difference between controlled and uncontrolled diabetics $(\mathrm{P}<0.001)$, with physical, psychological, and environmental health of patients with uncontrolled diabetes being affected the most (Table 5).

\section{Discussion}

In terms of psychological and social well-being and physical health, diabetes can have a profound effect on the QOL. Of all the chronic diseases, it is one of the most psychologically demanding diseases, with psychosocial factors associated with almost every aspect and treatment. ${ }^{16}$ Resolution of symptoms should not be the only goal of treatment; rather, it now necessitates a holistic approach targeting the overall improvement of QOL. ${ }^{16}$ Hence, we assessed the QOL in T2DM patients using the WHOQOL-BREF questionnaire and ADS.

The socio-demographic characteristics like age, male predominance, marital and economic status, diet

Table 2. Gender distribution of patients based on sociodemographic variables.

\begin{tabular}{lccc}
\hline $\begin{array}{l}\text { Socio-demographic } \\
\text { variables }\end{array}$ & \multicolumn{2}{c}{$\begin{array}{c}\text { Gender } \\
\text { No=520 }\end{array}$} & $\begin{array}{c}\text { Total } \\
\text { No (\%) }\end{array}$ \\
& $\begin{array}{c}\text { Male } \\
\text { No (\%) }\end{array}$ & $\begin{array}{c}\text { Female } \\
\text { No (\%) }\end{array}$ & \\
\hline Age range (years) & & & \\
$31-40$ & $6(2.3)$ & $6(2.3)$ & $12(2.3)$ \\
$41-50$ & $50(18.9)$ & $29(11.3)$ & $79(15.2)$ \\
$51-60$ & $95(36.0)$ & $103(40.2)$ & $198(38.1)$ \\
$61-70$ & $84(31.8)$ & $104(40.6)$ & $188(36.2)$ \\
$71-80$ & $25(9.5)$ & $12(4.7)$ & $37(7.1)$ \\
$81-90$ & $4(1.5)$ & $2(0.8)$ & $6(1.2)$ \\
\hline Education & & & \\
Illiterate & $29(11.0)$ & $79(30.9)$ & $108(20.8)$ \\
Primary & $67(25.4)$ & $88(34.4)$ & $155(29.8)$ \\
Secondary & $84(31.8)$ & $70(27.3)$ & $154(29.6)$ \\
$12^{\text {th }}$ grade & $60(22.7)$ & $11(4.3)$ & $71(13.7)$ \\
Graduation & $24(9.1)$ & $8(3.1)$ & $32(6.2)$ \\
\hline Occupation & & & \\
Housewife & - & $235(91.8)$ & $235(45.2)$ \\
Govt. employee & $7(2.7)$ & $2(0.8)$ & $9(1.7)$ \\
Private employee & $27(10.2)$ & $12(4.7)$ & $39(7.5)$ \\
Business & $117(44.3)$ & $2(0.8)$ & $119(22.7)$ \\
Others & $113(42.8)$ & $5(2.0)$ & $118(22.7)$ \\
\hline BMI (kg/m $\left.{ }^{2}\right)$ & & & \\
$<18.4$ & $4(1.51)$ & $7(2.73)$ & $11(2.11)$ \\
$18.5-22.9$ & $107(40.53)$ & $106(41.41)$ & $213(40.96)$ \\
$23-24.9$ & $76(28.78)$ & $67(26.17)$ & $143(27.5)$ \\
$\geq 25$ & $77(29.16)$ & $76(29.68)$ & $153(29.42)$ \\
\hline & &
\end{tabular}

No (\%), number (percentage); BMI, body mass index. 
pattern, and duration of the exercise of patients in the present study are consistent with previous studies on diabetes in India. ${ }^{17,18}$ The male predominance indicates that the number of male patients visiting the outpatient clinics is still higher than females in India as the latter give less importance to their health. Furthermore, the frequency of regular exercise among patients indicated increased awareness among them regarding the importance of exercise in controlling diabetes.

In the present study, most of the females had low educational status as compared to men. Furthermore, most of the male patients were middle-aged and employed in businesses while the majority of the female patients were housewives and had reached old age,

Table 3. Clinical variables of type 2 diabetes mellitus patients.

\begin{tabular}{|c|c|}
\hline Clinical variables & No $(\%)$ \\
\hline \multicolumn{2}{|l|}{ Family history of diabetes } \\
\hline Yes & $186(35.76)$ \\
\hline No & $113(21.73)$ \\
\hline Don't know & $221(42.5 \%)$ \\
\hline \multicolumn{2}{|l|}{ Symptoms } \\
\hline Polyuria & $172(33.1)$ \\
\hline Polydipsia & $49(9.4)$ \\
\hline Polyphagia & $56(10.8)$ \\
\hline$>$ One symptom & $150(28.8)$ \\
\hline All three & $15(2.9)$ \\
\hline Asymptomatic & $78(15)$ \\
\hline \multicolumn{2}{|l|}{ Associated diseases } \\
\hline Hypertension & $115(22.1)$ \\
\hline Ischemic heart disease & $05(0.96)$ \\
\hline Cerebrovascular accident & 0 \\
\hline Retinopathy & $23(4.42)$ \\
\hline Neuropathy & $28(5.38)$ \\
\hline Nephropathy & $01(0.19)$ \\
\hline Others & $26(5)$ \\
\hline Multiple co-morbidities & $262(50.38)$ \\
\hline None & $60(11.53)$ \\
\hline \multicolumn{2}{|l|}{ Duration of diabetes (years) } \\
\hline $0-5$ & $162(31.2)$ \\
\hline $6-10$ & $165(31.7)$ \\
\hline $11-15$ & $101(19.4)$ \\
\hline$>15$ & $92(17.7)$ \\
\hline \multicolumn{2}{|l|}{ Treatment } \\
\hline Oral hypoglycemic agents & $225(43.3)$ \\
\hline Insulin & $18(3.5)$ \\
\hline Both & $195(37.5)$ \\
\hline No treatment & $82(15.8)$ \\
\hline \multicolumn{2}{|l|}{ FBG level (mg/dL) } \\
\hline$<126$ & $293(56.3)$ \\
\hline$>126 \mathrm{mg} / \mathrm{dL}$ & $227(43.7)$ \\
\hline \multicolumn{2}{|l|}{ PPBG level (mg/dL) } \\
\hline$<180$ & $337(64.8)$ \\
\hline$>180$ & $183(35.2)$ \\
\hline \multicolumn{2}{|l|}{ HbA1c level (\%) } \\
\hline$<7$ & $169(32.5)$ \\
\hline$>7$ & $351(67.5)$ \\
\hline
\end{tabular}

FBG, fasting blood glucose; HbA1c, hemoglobin A1c; N (\%), number (percentage); PPBG, postprandial blood glucose. demonstrating that the chances of getting T2DM in females increased on reaching old age. This result agreed with Anumol et al. ${ }^{17}$ who found that more than half of the females with T2DM had a low education level and were housewives. ${ }^{17}$ Low educational status is associated with low health status as it possibly limits resources and information on environmental exposures and healthy behaviors.

Most of the patients in the present study had a family history of diabetes, like the study conducted by Patel et al..$^{13}$ Patients with a family history of diabetes have an $80 \%$ greater risk of developing diabetes. Furthermore, the postprandial glucose metabolism in Asian people is strongly associated with the family historyrelated incidence of diabetes. ${ }^{18}$ Polyuria was the most frequently occurring symptom among diabetic patients, as reported in the literature..$^{18}$ It occurs as a result of osmotic diuresis due to high glucose levels than excreted in the urine. Passively, the water follows the glucose concentration resulting in abnormally high urine output.

In the present study, patients had multiple comorbidities, with hypertension being the most commonly occurring comorbidity. Although the majority of the patients received oral hypoglycemic agents, many used both insulin and oral hypoglycemic agents. Although fasting and postprandial blood glucose levels were under control in many patients, most of them had their hemoglobin Alc levels above the normal range due to diabetes. Similar observations were made by Patel et al. ${ }^{13}$

Several factors have been identified as predictors of T2DM-related QOL. Age, duration of diabetes, associated comorbidities, treatment, and HbA1c level of patients significantly affected the QOL as patients aged $\geq 60$ with 6-10 years of diabetes, multiple comorbidities, oral hypoglycemic medication, and uncontrolled diabetes (HbAlc level $\geq 7 \mathrm{mmol} / \mathrm{mol}$ ) had very poor and poor QOL. This is consistent with Somappa et al.'s study in which ${ }^{19}$ patients with HbA1c level $\geq 7$ $\mathrm{mmol} / \mathrm{mol}$ (uncontrolled diabetes) showed poor QOL. ${ }^{19}$ These findings demonstrate that $\mathrm{HbA} 1 \mathrm{c}$ levels are essential predictors of QOL among people with diabetes, and it is crucial to maintain these levels to control T2DM for improved QOL.

The mean ADS score of patients with uncontrolled diabetes was higher than that of patients with controlled diabetes. This is consistent with the findings of Patel et al., who reported that the mean ADS score was $19.9 \pm 3.4 .{ }^{13}$ Furthermore, the overall WHOQOLBREF score concerning all its five domains was significantly low for uncontrolled than controlled diabetes patients in the present study. This is in accordance with a study from UAE, ${ }^{9}$ in which the physical and social domains scored high among controlled diabetics. The reason may be that, like Indians, the UAE people also enjoy strong family connections and social 
relationships. However, the findings of a study from Nigeria were in contrast with our study's results as it reported higher QOL scores in the social domain and lower scores in physical, environmental, and psychological domains than our study. ${ }^{20}$ The observed difference in some of the domains could be due to socio-cultural factors, despite Nigeria being a developing country like India.

Our study showed a significant difference for major domains in QOL instruments and depicted poorer QOL in uncontrolled diabetics than controlled diabetics. Considering it as an important finding of our study, we suggest the effectiveness of both the instruments in evaluating the impact of disease control on the QOL of diabetic patients.

Our study has its limitations. It was a single-centered study in India and included patients from lower socioeconomic classes and only T2DM. Therefore, the study's findings may not be generalized for all Indian patients and both types of diabetes. Future studies are recommended to evaluate the effect of therapeutic interventions on the QOL of diabetic patients. Hence, a future prospective study should be undertaken with follow-up visits to observe the impact.

Table 4. Association of QOL with age, duration of diabetes, associated comorbidities, treatment, HBA1c, and BMI.

\begin{tabular}{|c|c|c|c|c|c|}
\hline \multirow[t]{2}{*}{ Variables } & \multicolumn{4}{|c|}{ WHOQOL-BREF ( $\mathrm{No}=520)$} & \multirow[t]{2}{*}{ P-value* } \\
\hline & Very poor & Poor & Average & Good & \\
\hline \multicolumn{6}{|l|}{ Age (years) } \\
\hline$\leq 60$ & $42(8.07)$ & $20(3.84)$ & $144(27.69)$ & $38(7.30)$ & $<0.001^{*}$ \\
\hline$\geq 60$ & $44(8.46)$ & $92(17.69)$ & $127(24.42)$ & $13(2.5)$ & \\
\hline \multicolumn{6}{|l|}{ Duration of diabetes (years) } \\
\hline $0-5$ & $29(5.57)$ & $14(2.69)$ & $90(17.30)$ & $29(5.57)$ & $<0.001^{*}$ \\
\hline $6-10$ & $31(5.96)$ & $24(4.61)$ & $92(17.69)$ & $18(3.46)$ & \\
\hline $11-15$ & $15(2.88)$ & $16(3.07)$ & $66(12.69)$ & $4(0.76)$ & \\
\hline$>15$ & $11(2.11)$ & $58(11.15)$ & $23(4.42)$ & $0(0)$ & \\
\hline \multicolumn{6}{|l|}{ Associated comorbidities } \\
\hline Single co-morbidity & $33(6.34)$ & $35(6.73)$ & $100(19.23)$ & $34(6.53)$ & $<0.001 *$ \\
\hline Multiple co-morbidities & $45(8.65)$ & $71(13.65)$ & $132(25.38)$ & $10(1.92)$ & \\
\hline None & $8(1.53)$ & $6(1.15)$ & $39(7.52)$ & $7(1.34)$ & \\
\hline \multicolumn{6}{|l|}{ Treatment } \\
\hline Oral hypoglycemic agents & $31(5.96)$ & $68(13.07)$ & $97(18.65)$ & $29(5.57)$ & $<0.001 *$ \\
\hline Insulin & $2(0.38)$ & $4(0.76)$ & $11(2.11)$ & $1(0.19)$ & \\
\hline Both & $39(7.5)$ & $23(4.42)$ & $116(22.30)$ & $17(3.26)$ & \\
\hline None & $14(2.69)$ & $17(3.26)$ & $47(9.03)$ & $4(0.76)$ & \\
\hline \multicolumn{6}{|l|}{ HbA1c (mmol/mol) } \\
\hline$<7$ (controlled diabetes) & $0(0)$ & $27(5.19)$ & $114(21.92)$ & $28(5.38)$ & $<0.001 *$ \\
\hline$\geq 7$ (uncontrolled diabetes) & $86(16.53)$ & $85(16.34)$ & $157(30.19)$ & $23(4.42)$ & \\
\hline \multicolumn{6}{|l|}{ BMI $\left(\mathrm{kg} / \mathrm{m}^{2}\right)$} \\
\hline$<18.4$ & $2(0.38)$ & $1(0.19)$ & $6(1.15)$ & $2(0.38)$ & 0.1885 \\
\hline $18.5-22.9$ & $40(7.69)$ & $43(8.26)$ & $108(20.76)$ & $22(4.23)$ & \\
\hline $23-24.9$ & $16(3.07)$ & $39(7.52)$ & $70(13.46)$ & $18(3.46)$ & \\
\hline$>25$ & $28(5.38)$ & $29(5.57)$ & $87(16.73)$ & $9(1.73)$ & \\
\hline
\end{tabular}

BMI, body-mass index; C, Chi-square test of independence; HbAlc, hemoglobin Alc; mmol/mol, millimoles per mole; N (\%), number (percentage); WHOQOL-BREF, World Health Organization Quality of Life-BREF. *Highly significant.

Table 5. Difference between QOL in controlled and uncontrolled diabetes in terms of ADS and WHOQOL-BREF domains.

\begin{tabular}{lcccc}
\hline Domain & $\begin{array}{c}\text { For all scores } \\
(\mathbf{m}=a n \pm \text { SD) }\end{array}$ & $\begin{array}{c}\text { Controlled diabetes } \\
(\mathbf{m e a n} \pm \text { SD) }\end{array}$ & $\begin{array}{c}\text { Uncontrolled diabetes } \\
(\mathbf{m e a n} \pm \text { SD) }\end{array}$ & P-value $^{\circ}$ \\
\hline ADS (scores) & & & & \\
$\quad$ ADS & $19.03 \pm 2.87$ & $18.50 \pm 3.08$ & $19.29 \pm 2.73$ & 0.003 \\
\hline WHOQOL-BREF (scores) & & & & \\
$\quad$ Overall General Health & $5.4 \pm 1.23$ & $6.0 \pm 1.13$ & $5.1 \pm 1.18$ & $<0.001^{*}$ \\
Physical & $17.8 \pm 4.64$ & $19.35 \pm 5.08$ & $17.14 \pm 4.23$ & $<0.001^{*}$ \\
Psychological & $16.4 \pm 2.88$ & $17.3 \pm 3.31$ & $15.9 \pm 2.53$ & $<0.001^{*}$ \\
$\quad$ Social & $7.4 \pm 1.17$ & $7.91 \pm 1.22$ & $7.17 \pm 1.07$ & $<0.001^{*}$ \\
Environmental & $23.4 \pm 5.8$ & $24.6 \pm 4.52$ & $22.83 \pm 6.26$ & $<0.001^{*}$ \\
\hline
\end{tabular}

ADS, Appraisal of Diabetes Scale; SD, standard deviation; WHOQOL-BREF, World Health Organization Quality of Life BREF; 'unpaired 't' test. *Highly significant. 


\section{Conclusions}

The QOL was more impaired in uncontrolled diabetics in comparison to controlled diabetics in T2DM. Both the instruments, i.e., generic WHOQOL-BREF and disease-specific ADS, were significantly correlated with uncontrolled diabetes being affected the most. They were reliable and effective in measuring the QOL in T2DM. Age, duration of diabetes, associated comorbidities, treatment, and $\mathrm{HbAlc}$ level of patients were important predictors of QOL as they significantly affected the QOL of T2DM patients.

\section{References}

1. Powers AC. Diabetes mellitus. In: Longo D, Kasper D, Jameson J, Fauci A, Hauser S, Loscalzo J, eds. Harrison's principles of internal medicine, 18th ed. New York, NY: McGraw Hill; 2012. pp 2968-3003.

2. Zheng Y, Ley SH, Hu FB. Global aetiology and epidemiology of type 2 diabetes mellitus and its complications. Nat Rev Endocrinol 2018;14:88-98.

3. Ali S, Stone MA, Peters JL, et al. The prevalence of comorbid depression in adults with type 2 diabetes: A systematic review and meta-analysis. Diabet Med 2006;23:1165-73.

4. World Health Organization. WHOQOL-BREF: introduction, administration, scoring and generic version of the assessment: field trial version, December 1996. Geneva: World Health Organization; 1996.

5. Lin CY, Lee TY, Sun ZJ, et al. Development of diabetesspecific quality of life module to be in conjunction with the World Health Organization quality of life scale brief version (WHOQOL-BREF). Health Qual Life Outcomes 2017;15:167.

6. Carey MP, Jorgensen RS, Weinstock RS, et al. Reliability and validity of the appraisal of diabetes scale. J Behav Med 1991;14:43-51.

7. Garratt AM, Schmidt L, Fitzpatrick R. Patient-assessed health outcome measures for diabetes: a structured review. Diabet Med 2002;19:1-11.

8. Papadopoulos AA, Kontodimopoulos N, Frydas A, et al.
Predictors of health-related quality of life in type II diabetic patients in Greece. BMC Public Health 2007; 7:186.

9. Bani-Issa W. Evaluation of the health-related quality of life of Emirati people with diabetes: integration of sociodemographic and disease related variables. East Mediterr Health J 2011;17:825-30.

10. Borrott N, Bush R. Measuring quality of life among those with type 2 diabetes in primary care. Queensland: Healthy Communities Research Centre, University of Queensland; 2008. pp 1-25.

11. Imayama I, Plotnikoff RC, Courneya KS, Johnson JA. Determinants of quality of life in adults with type 1 and type 2 diabetes. Health Qual Life Outcomes 2011;9:115.

12. Daniel WW, editor. Biostatistics: a foundation for analysis in the health sciences. 7th ed. New York: John Wiley \& Sons; 1999.

13. Patel B, Oza B, Patel K, et al. Health related quality of life in type-2 diabetic patients in Western India using World Health Organization Quality of Life-BREF and appraisal of diabetes scale. Int J Diabetes Dev Ctries 2014;34:100-7.

14. Prasad BG. Social classification of Indian families. J Indian Med Assoc 1968;51:365-6.

15. All-India Consumer Price Index (General) for Industrial Workers (Base 1982=100); November 3 2015. Available from: http://cyberjournalist.org.in/manisana/aicpinew. html Accessed: 20 July 2016.

16. Goldney RD, Phillips PJ, Fisher J, Wilson DH. Diabetes, depression, and quality of life: a population study. Diabetes Care 2004;27:1066-70.

17. Ramesh R, Kumar SV, Gopinath S, et al. Diabetic knowledge of rural community and drug utilization pattern in a tertiary care hospital. Int J Pharm Life Sci 2011;2:531-5.

18. Patel M, Patel IM, Patel YM, Rathi SK. A hospital-based observational study of type 2 diabetic subjects from $\mathrm{Gu}-$ jarat, India. J Health Popul Nutr 2011;29:265-72.

19. Srinivas HK, Venkatesha M, Prasad R. Quality of life assessment among type 2 diabetic patients in rural tertiary centre. Int J Med Sci Public Health 2014;3:415-7.

20. Kolawole BA, Mosaku SK, Ikem RT. A comparison of two measures of quality of life of Nigerian clinic patients with type 2 diabetes mellitus. Afr Health Sci 2009;9:161-6. 